\title{
4
}

\section{Input Utilization and Agricultural Labor Productivity: A Gender Analysis}

\author{
A. M. Rufai, K. K. Salman, and M. B. Salawu
}

\subsection{Introduction}

Agriculture employs about 65\% of Africa's labor force (World Bank 2013) and the sector has been identified as the major source of income of most rural households. Sub-Saharan Africa ranks high in the world in terms of the proportion of people living in poverty, and agriculture has been identified to have the potentials of reducing poverty and promoting economic development in the region. David (2010) however explained that there is the need to improve the productivity of the sector for it to have higher impacts on aggregate economic indicators and ultimately reduce poverty. Failure to develop the agricultural sector in the region could be associated with the low performance of labor. McCullough (2015) revealed that despite the fact that countries in Sub-Saharan Africa have the highest level of value added through the agricultural sector, the region has the lowest labor productivity.

\footnotetext{
A. M. Rufai $(\bowtie) \bullet$ K. K. Salman • M. B. Salawu

University of Ibadan, Ibadan, Nigeria 
In addition to land and capital, labor is identified as one of the most important and effective factors of agricultural production (Biniaz 2014). According to Oluyole et al. (2007), the availability of labor determines the quantity and quality of output as it influences planting precision, weed control, timely harvest and crop processing. Agriculture in Nigeria is labor intensive as the sector employs more than half of the labor force in the country. However, despite the high level of human resource, the contribution of the sector to the economic growth has continued to reduce over the years (Manyong et al. 2005; Mohammed-Lawal and Atte 2006). The low productivity has been associated with the fact that the sector is mostly made up of small scale farmers who still use rudimentary production techniques which makes them highly dependent on manual labor (Oluyole et al. 2013).

Family labor is an important source of manpower in agriculture. Women especially in the rural areas are known to play crucial roles in household farming activities, thus contributing significantly to the amount of labor available for agriculture. The increasing out-migration of men from rural areas and their participation in off-farm work has left agriculture more in the hands of women (Lastarria-corhiel 2006).

Women's work in agriculture has become more visible as their involvement in agricultural production has deepened in response to the economic opportunities in commercial agriculture and the rising need for them to provide for the household (Lastarria-corhiel 2006). However, despite their increased involvement in agriculture, significant differences have been identified in the level of productivity of men and women. The traditional system of division of labor where women are expected to care for the house and still participate in agricultural activities may restrict their availability for agricultural production, thus reducing the total area under crop cultivation due to labor shortages (Kwaramba 1997). Edet et al. (2016) explain that the availability of labor for farm activities determines the extent of work that can be done and ultimately the productivity of the sector.

The productivity of labor in agriculture is highly dependent on the availability of inputs and the quality of work done by labor. Okoye et al. (2008) explained that the proper allocation of inputs could assist farmers to make efficient and effective use of labor and ultimately improve 
productivity. The lower productivity in female-managed farms is an indication of the differences in the factors of agricultural production (i.e. both input and management) between genders. Generally, the production capacity of farm households in Nigeria is limited by their poor access to inputs such as land (as a result of the expanding population), new technology and credit facilities. However, women face greater vulnerabilities in agriculture mainly because of their poor access to inputs coupled with their relative lack of education and heavy burden of unpaid domestic work (Phillip et al. 2009). Ogunlela and Mukhtar (2009) explain that high levels of gender imbalance combined with social, religious, psychological and biological factors promote discriminations against women in terms of employment, education and access to resources.

The variations in the extent of access to inputs between gender in Nigeria and the low contribution of the agricultural sector to the GDP in the country despite the high level of labor participation makes it important to examine the extent of input utilization and understand how it influences the productivity of labor in agriculture based on gender. Such assessments are germane for the formulation of effective policies that would promote efficient use of labor and other inputs, reduce poverty in agricultural households and increase the contribution of the agricultural sector to economic growth.

The main objective of the chapter is to explore the influences of input utilization on labor productivity among men and women in Nigeria. The specific objectives of the study are to:

- assess the extent of input utilization based on gender;

- examine the extent and type of labor utilized and the productivity of labor;

- identify the factors that determine the utilization of inputs among farmers; and

- analyze the effects of input utilization on the productivity of labor.

While the efficient use of resources in agriculture is important, an effective use of the vast human resources available for agriculture in Nigeria could promote rapid agricultural development as according to 
(Polyzos and Arabatzis 2005) it remains the most important factor in the production process. For agriculture to result in economic growth and reduce poverty, it is necessary for output to grow at a faster rate than the labor force in the population (Okoye et al. 2008). In Nigeria, studies such as, Anyaegbunam et al. (2010) and Okoye et al. (2008) have examined the effects of inputs on the productivity of labor while others such as Ogunniyi et al. (2012) and Umar et al. (2010) considered the differences in the productivity between males and females in their assessments. However, most of the studies on input utilization and labor productivity in Nigeria were focused on specific crops and farmers from certain parts of the country and not the country as a whole and hence lacked national representation. The availability of such information would be a substantial input in understanding the agricultural labor market dynamics in Nigeria. Also most of the studies often do not control for plot, household and village/community characteristics that could influence the gender gap in labor productivity. Ragasa et al. (2012) explains that the noninclusion of such variables in the assessment of productivity in agriculture often leads to biased results. Also Clark (2013) opined that the inclusion of such variables does not only explain the gender gap in productivity, they also provide important insights into key variables that drive differences. This study also uses the quantile regression to assess the effects of inputs on labor productivity compared to the ordinary least squares (OLS) used in most studies. This method compared to the OLS gives a broader description of a dependent variable as a conditional function of a set of covariates (Kaditi and Nitsi 2010). Kaditi and Nitsi (2009) explain that the heterogeneity in farm data which leads to the problem of heteroskedasticity and resultant biased estimates makes quantile regression particularly suitable for its analysis.

Policies addressing agricultural productivity are masculine in nature and they often do not promote women empowerment by reducing the gender productivity differential and ensuring access to resources among women in agriculture. For the agricultural sector to promote significant economic development in Nigeria, the important roles of women, the increasing feminization of agriculture and the challenges faced by women need to be well understood and operationalized in policymaking across the country. Understanding how input utilization influences labor 
productivity across gender is important in making decisions about the implementation of agricultural policies and interventions in various parts of the country. The findings from such studies are also vital in the formulation of policies that are concerned with promoting food security in the country as increasing farmers productivity translates to increasing the amount of food available within the country.

\subsection{Methodology}

Scope of study: Nigeria is located in West Africa and shares borders with the Republic of Benin in the west, Chad and Cameroon in the east and Niger in the north. The country has a land area of approximately 923,768 square kilometers with $1.4 \%$ covered by water. It has a population of about 184,551,471 (Worldometer n.d.) and a rural population of about $93,589,090$. About $90 \%$ of the rural population is employed in agriculture according to International Fund for Agricultural Development (IFAD). The three largest and most influential ethnic groups in Nigeria are the Hausa, Igbo and Yoruba, and based on this, the country can be roughly split into three regions.

Data: The general household survey (GHS) data for Nigeria collected by the National Bureau of statistics in collaboration with the Federal Ministry of Agriculture and Rural Development and the World Bank would be used for this study. The sampling frame for the data is based on the 2006 housing and population census conducted by the National Population Commission (NPopC). The sampling frame was made up of about 662,000 enumeration areas (EAs). The master frame was also generated at the local government areas (LGAs). The National Integrated Survey of Households 2007/2012 Master Frame Sample (NISH-MSF) was constructed by pooling LGAs in the master areas by state. A systematic sample of 200 EAs was then selected with equal probability across all LGAs within the state. The sample EAs for the GHS was based on a sub-sample NISH-MSF which are replicates generated from the NISH-MSF frame. A two stage sampling procedure was used in collecting the GHS data. In the first stage, the EAs (or primary sampling units) were selected based on the probability proportional to size (PPS) of the total EAs in each 
state and the Federal Capital Territory (FCT) and the total number of households listed in each of the EAs. The second stage involved the selection of ten households per EA by the systematic random sampling procedure.

The data is nationally representative and contains information about household characteristics, literacy rates, off-farm income generating activities, paid and unpaid employments, agricultural practices and output, labor, wage rates and farm characteristics collected from a sample of 5000 households. The data is also representative at rural and urban levels, and across the geopolitical zones of the country. The data contains adequate information that would allow the researcher answer the key questions of this research. The data can be downloaded at http://microdata. worldbank.org/index.php/catalog/1952.

\subsection{Data Analysis}

Descriptive statistics: This involved the use of tables, frequency distribution, means, percentages and standard deviation in analyzing the use of inputs and labor productivity by gender. The use of inputs was assessed across the six geopolitical zones in Nigeria.

Principal Components Analysis (PCA): The input index was generated using the Principal Component analysis (PCA). The PCA finds the axis system defined by principal directions of variance $(\alpha)$ in a given data set. It linearly transforms data into a substantially smaller set of uncorrelated variables called principal components that contain most of the information in the original data. The principal components are found by calculating the eigen vectors and eigen values of the covariance matrix. Following Kolenikov and Angeles (2004), if a random variable $X$ with dimensions $n$ with finite nxn variance-covariance matrix;

$$
V[X]=\varepsilon
$$


The principal component $(Y j)_{0}$ of variable $X 1 \ldots X \mathrm{n}$ are linear combinations $\alpha_{i j} \ldots \alpha_{i n}$ such that:

$$
y_{j}=a_{j} x
$$

where $j=1 \ldots n$.

Solving the eigen problem for matrix $\varepsilon$ involves finding $\lambda$ and $\alpha$ such that $\varepsilon \alpha=\lambda \alpha$ which gives the set of principal components weights $\alpha$ (or factor loadings), the linear combinations $\alpha^{\prime} \mathrm{x}$ (or factor scores) and eigen values $\lambda_{1} \geq \lambda_{2} \geq \ldots . \lambda n$. The variance $v\left[\alpha^{\prime} \mathrm{x}=\lambda_{k}\right]$ so that eigen values are the variances of the linear combinations. The index is generated as a weighted average of the variable scores with weights equal to the loadings of the first principal component.

$$
c_{i}=\sum_{i=1}^{n} w_{1} x_{1}
$$

where $c=$ composite index, $w=$ weight attributed and $n=$ number of variables

Labor productivity: This is the ratio of output ( $y$ ) and labor input (l). It is a partial productivity measure which is largely dependent on the effective use of other inputs (Organization of Economic Co-operative and Development-OECD 2011). Labor productivity $\left(y_{p}\right)$ is expressed as:

$$
y_{p}=\frac{\text { volume measure of output }}{\text { Measure of labour input }}=\frac{Y}{L}
$$

The factors that explain the productivity are thereafter unveiled in a labor productivity model given as:

$$
y_{p}=f(P, I, H)
$$


where $y_{p}=$ Labor productivity, $P=$ Plot characteristics (Land size, cropping system), $I=$ other inputs (fertilizer, herbicides, pesticides, machinery and animal traction) and $H=$ characteristics of plot owner (socioeconomic and other household characteristics).

Equation (4.2) can be modeled explicitly as:

$$
y_{f n}=\beta_{0}+\beta_{1} p_{f n}+\beta_{2} I_{f n}+\beta_{3} H_{f n}+e_{f n}
$$

where $y_{f n}=$ labor productivity on plot $\mathrm{f}$ in household $\mathrm{n}, p_{f n}=$ plot characteristics of plot $f, I_{f n}=$ use of production inputs on plot of $f, H_{f n}=$ characteristics of owner of plot $f$ and $e_{f n}$ is the error term.

Quantile Model: To estimate the labor productivity model, a quantile regression was employed. The conditional $\tau^{\text {th }}$ quantile of $y p(r \in[0,1])$ given a covariate vector $\mathrm{x}$ is expressed linearly in logarithms given a conditional quantile function

$$
Q_{\text {lny }}(\tau / x)=\beta(\tau) \ln x
$$

Adapting the labor productivity model in Eqs. 3 and 4 gives:

$$
Q_{l n y}\left(\frac{\tau}{x}\right)=\beta_{0}+\beta_{1}(\tau) p_{f n}+\beta_{2}(\tau) I_{f n}+\beta_{3}(\tau) H_{f n}+F^{\prime}(\tau)
$$

To further address the problem of heteroskedasticity, the bootstrapped quantile regression was used to obtain robust standard errors. According to Singh and Xie, bootstrapping involves the use of a data sample to create a large number of samples through resampling. It is a statistical function of the form

$$
T=(\tilde{\theta}-\theta) / \mathrm{SE}
$$


where $\theta=$ Population parameter, $\tilde{\theta}=$ sample parameter (bootstrap) and $\mathrm{SE}=$ sample estimate of the standard error of $\tilde{\theta}$ which brings extra accuracy.

\subsection{Results}

\subsubsection{Input Utilization Based on Gender}

The level of input utilization on male- and female-managed plots was presented in Table 4.1. Generally less than $45 \%$ of the farmers had used fertilizer. Almost $45 \%$ of the males had used fertilizer while less than a quarter of the females had used the input on their plots. Even though females had a higher minimum quantity of $100 \mathrm{~kg}$, males had a higher maximum quantity of $43,000 \mathrm{~kg}$ of fertilizer compared to the maximum of $20,000 \mathrm{~kg}$ among females. In assessing the constraints encountered by women in Agriculture in Nigeria, Fabiyi et al. (2007) explained that women identified that the high costs of inputs and late delivery of inputs, especially fertilizer, was a major constraint. Ajani and Igbokwe (2011) also identified that major constraints encountered by women in performing new roles with the feminization of agriculture were the lack of farm inputs such as fertilizer and herbicides.

For pesticides, less than $10 \%$ of the farmers had used the input on their plots. Even though a higher proportion of females (11.59\%) had used the input, males used more pesticides than females as males had a maximum quantity of $40,000 \mathrm{~kg}$ compared to the maximum quantity of $2400 \mathrm{~kg}$ among female-managed plots. Similarly, over 30\% of the females had used herbicides on their plots while less than a quarter of the males had used the input. However, males had a higher quantity of $10,000 \mathrm{~kg}$ compared to $2400 \mathrm{~kg}$ on female plots. For machinery/equipment, less than a quarter of males and females had used the input. Males had a higher maximum value of 40 machines/ equipment while a higher proportion of women $(20.86 \%)$ had used the input on their farms. This implies that even though higher proportions of females had used pesticides, herbicides and machines/equipment 


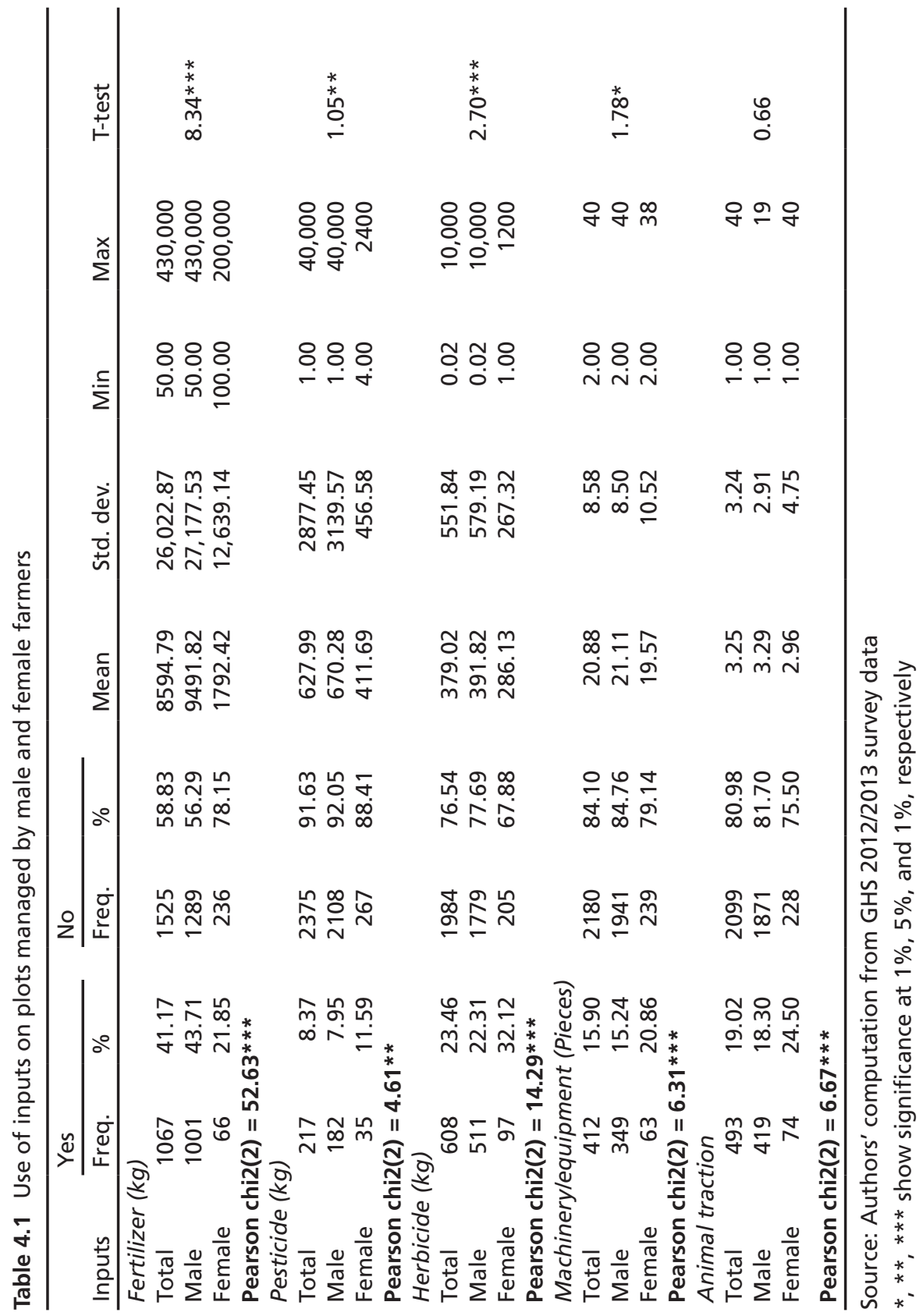


on their plots, the quantities used among them were smaller when compared to the quantities utilized on male-managed plots. The results of the T-test show there was significant difference in the quantity of fertilizer, pesticides, herbicides, machinery and equipment used on male- and female-managed farms. Ogunniyi et al. (2012), in assessing input utilization among male and female Cocoa farmers, revealed that male farmers used higher quantities of pesticides and insecticides on their farms than female farmers.

Only about $20 \%$ of the farmers had utilized animal traction on their farms. It seemed to be utilized more on female-managed plots as $24.50 \%$ of females had used the input compared to $18.30 \%$ of male-managed plots while females had also used a higher maximum number of animals (40 animals) compared to males (19 animals). However, there was no significant difference in the number of animals used for traction on both male and female farms. The results of the Pearson's chi-square statistic also revealed that there was significant difference in the use of inputs across male- and female-managed farms in Nigeria. This implies that while a higher proportion of male-managed plots used fertilizer, a higher proportion of female-managed farms used pesticides, herbicides, machinery and equipment and animal traction.

Across the zones as shown in Table 4.2, all the females in the North-West had used fertilizer on their plots while none of the females in the SouthWest had used the input on their farms. In the North-Central and NorthEast more males had used fertilizer on their plots while in the South-East and South-South there was no significant difference in the proportion of males and females that had used fertilizer on their plots. For pesticides, none of the women in the North-Central and North-West had used the input while higher proportion of females had used the input in the NorthEast and South-South. None of the females in the North-Central zone had also used herbicides on their farms. However, compared to males, a higher proportion of females had used herbicides in the North-East, South-East and South-West. For machinery and equipment, none of the females in the North-East had used them while a higher proportion of females had used them in the other zones except the North-Central. Animal traction had not been used by females in the North-Central and North-East while a higher proportion of males had used them in the other zones. 


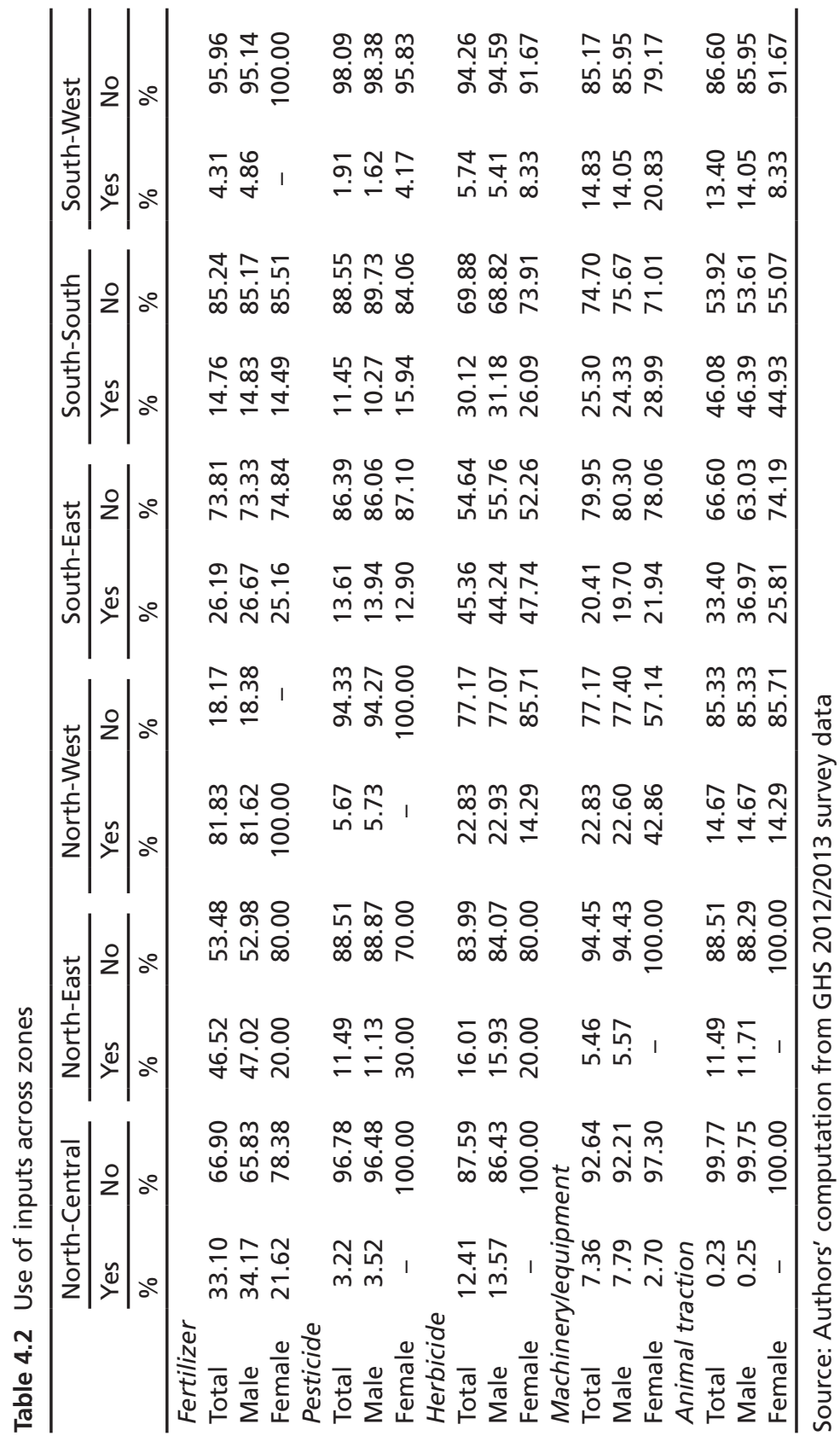




\subsubsection{Labor Utilization and Productivity Among Farmers Based on Gender}

\subsubsection{Family and Hired Labor Use}

The quantity of family and hired labor (men, women and children) used by male and female farmers was assessed as shown in Table 4.3. The average man-hours used of family labor on male and female plots were 199,468.70 man-hours and 175,203.60 man-hours, respectively. For hired labor, the average man-hours used on male and female plots was 588.48 man-hours and 833.32 man-hours, respectively. This indicates that, on average, female-managed plots used less family labor and more of hired when compared to male-managed ones. The average of hired

Table 4.3 Labor input use

\begin{tabular}{|c|c|c|c|c|c|}
\hline & Mean & Std. dev. & Min & Max & T-test \\
\hline \multicolumn{6}{|c|}{ Family labor } \\
\hline Total & $196,641.00$ & $804,835.00$ & 0.00 & $23,400,000.00$ & \multirow[t]{3}{*}{0.59} \\
\hline Male & $199,468.70$ & $824,542.90$ & 0.00 & $23,400,000.00$ & \\
\hline Female & $175,203.60$ & $636,546.90$ & 8.00 & $6,865,218.00$ & \\
\hline \multicolumn{6}{|c|}{ Hired labor } \\
\hline \multicolumn{6}{|c|}{ Total hired labor } \\
\hline Total & 617.00 & 3130.44 & 0.00 & $87,499.38$ & \multirow[t]{4}{*}{$2.64 * * *$} \\
\hline Male & 588.48 & 2761.82 & 0.00 & $85,261.08$ & \\
\hline Female & 833.32 & 5478.61 & 0.00 & $87,499.38$ & \\
\hline \multicolumn{5}{|l|}{ Men } & \\
\hline Total & 394.44 & 2354.33 & 0.00 & $85,005.00$ & \multirow[t]{3}{*}{0.27} \\
\hline Male & 390.17 & 2374.17 & 0.00 & $85,005.00$ & \\
\hline Female & 426.76 & 2201.47 & 0.00 & $31,368.00$ & \\
\hline \multicolumn{6}{|l|}{ Women } \\
\hline Total & 198.61 & 1972.33 & 0.00 & $87,395.88$ & \multirow[t]{3}{*}{$1.81 * *$} \\
\hline Male & 172.06 & 1032.25 & 0.00 & $30,809.63$ & \\
\hline Female & 399.93 & 5033.54 & 0.00 & $87,395.88$ & \\
\hline \multicolumn{6}{|l|}{ Children } \\
\hline Total & 23.96 & 284.06 & 0.00 & $12,804.00$ & \multirow[t]{3}{*}{$2.91 * * *$} \\
\hline Male & 26.24 & 301.77 & 0.00 & $12,804.00$ & \\
\hline Female & 6.63 & 41.24 & 0.00 & 185.60 & \\
\hline
\end{tabular}

Source: Authors' computation from GHS 2012/2013 survey data

*significant at $1 \%, * *$ significant at $5 \%, * * *$ significant at $1 \%$ 
men, women and children used across the plots were 394.44, 198.61 and 23.96 man-hours respectively.

Generally, Female-managed plots had a higher mean of 426.76 manhours from hired men when compared to male-managed plots. However, male-managed plots had a higher maximum labor (85,005 man-hours) spent working on plots by hired men. Hired females ${ }^{1}$ were utilized more on female-managed plots as they had a higher average and maximum labor of 399.93 man-hours and 87,395.88man-hours, respectively compared to 172.06 man-hours and 30,809.63 man-hours on male-managed plots. More child labor was used on male-managed plots compared to those managed by females. The average and maximum time spent by children on male plots was 26.24 man-hours and 12,804.00 man-hours. However, on female plots, an average labor of 6.63 man-hours was used by children and the maximum labor was 185.60 man-hours. There was a significant difference in the quantity of total hired labor, female hired labor and child hired labor between male- and female-managed plots in Nigeria; however, there was no significant difference in the amount of family labor and hired male labor.

Across the zones, as revealed in Table 4.4, female farmers in the SouthSouth and South-West had higher means of time spent by male labor on their farms while in the North-Central and South-South they had a higher mean of time spent by female labor when compared to malemanaged farms. The proportions of family and hired labor used on male and female plots vary with location in Nigeria as Obasi and Kanu (2014) found that male farmers had more access to hired labor than their female counterparts in Imo state while Ogunniyi et al. (2012) found that females used more hired labor and less family labor when compared to men in Ondo state.

\subsubsection{Labor Productivity}

In Table 4.5, male-managed plots had higher value of outputs with an average of $\$ 159,344.10$ and a maximum of $\$ 3,059,000$ while femalemanaged ones had an average of $\$ 133,138.60$ and a maximum value of 1,590,000. The amount of labor utilized on male-managed plots was higher as they had an average of 208,266.60 man-hours while females 


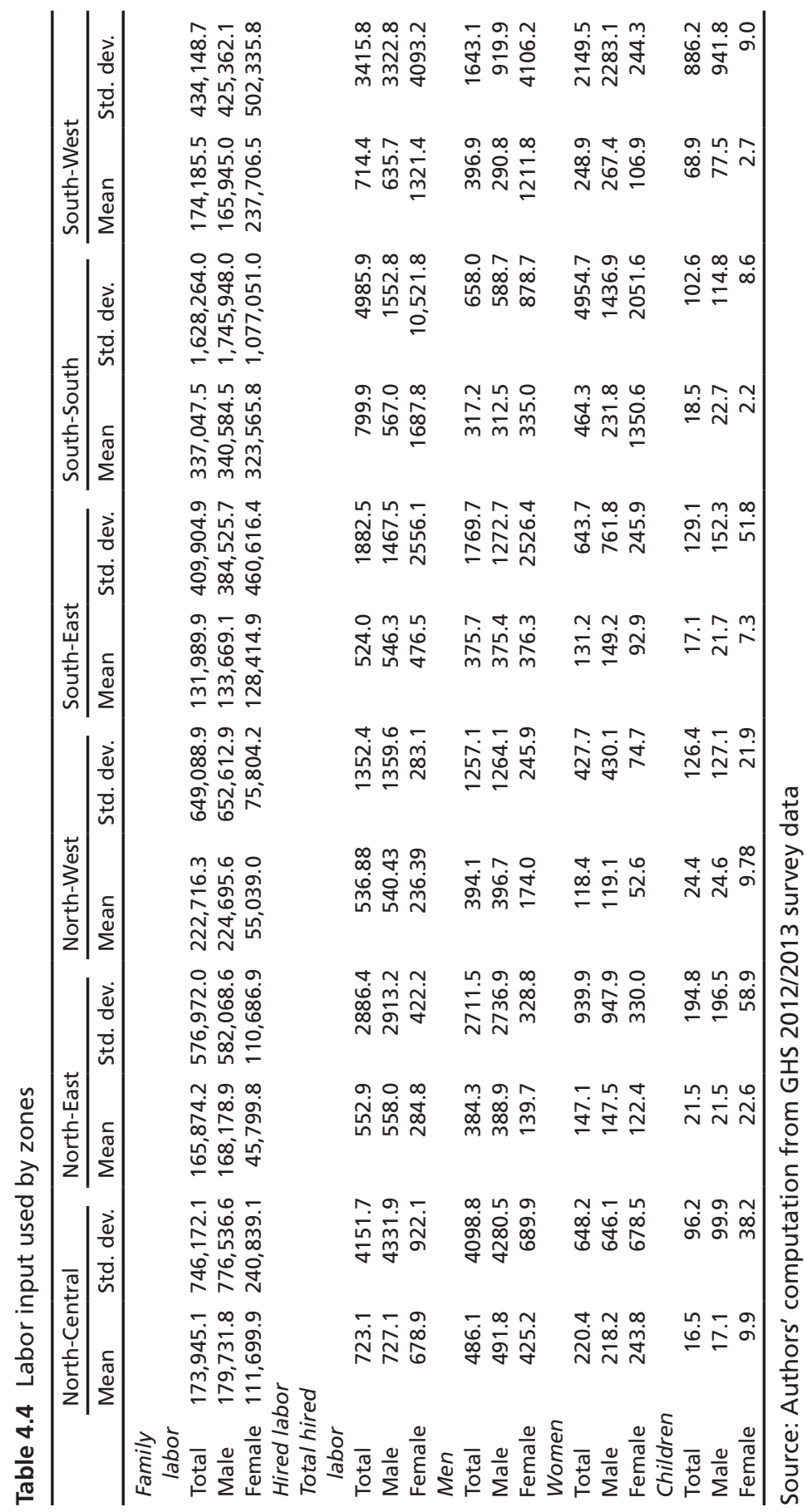


Table 4.5 Labor productivity based on gender

\begin{tabular}{|c|c|c|c|c|}
\hline Productivity & Mean & Std. dev. & Min & Max \\
\hline \multicolumn{5}{|c|}{ Value of output (\#) } \\
\hline Total & $156,290.90$ & $226,417.70$ & 500.00 & $3,059,000.00$ \\
\hline Male & $159,344.10$ & $226,417.70$ & 500.00 & $3,059,000.00$ \\
\hline Female & $133,138.60$ & $191,071.80$ & 500.00 & $1,590,000.00$ \\
\hline \multicolumn{5}{|c|}{ Total labor (man-hour) } \\
\hline Total & $204,576.20$ & $875,834.70$ & 21.00 & $23,400,000.00$ \\
\hline Male & $208,266.60$ & $902,707.60$ & 21.00 & $23,400,000.00$ \\
\hline Female & $176,592.20$ & $636,619.80$ & 162.00 & $6,865,532.00$ \\
\hline \multicolumn{5}{|c|}{ Labor productivity ( $\# / m a n-h o u r)$} \\
\hline Total & 48.93 & 275.64 & 0.01 & 9976.19 \\
\hline Male & 49.07 & 287.49 & 0.01 & 9976.19 \\
\hline Female & 47.86 & 159.59 & 0.02 & 1376.81 \\
\hline
\end{tabular}

Source: Authors' computation from GHS 2012/2013 survey data

had an average of 176,592.20 man-hours. Labor productivity was therefore higher on male-managed plots with an average of $\mathrm{N} 49.07 /$ man-hour and a maximum value of $\$ 996.19 /$ man-hour compared to female-managed plots with an average of $\$ 47.86 /$ man-hour and a maximum of $1376.81 /$ man-hour. Palacios-Lopez and Lopez (2015) explained that in Sub-Saharan Africa, land and labor productivity were higher in plots managed by male headed households; however, the gender difference was greater for labor productivity.

\subsubsection{Effects of Input Utilization on Labor Productivity by Gender}

\subsubsection{Gender-Specific Labor Productivity Model (Male)}

In the male model in Table 4.6, the results from the OLS when compared to the results from the quantile regression seem very similar. However, while three variables were significant in the OLS, four (4), four (4), three (2) and two (2) variables were significant in the 25th, 50th, 75th and 90th quantiles, respectively. The variation in the number of significant variables across the quantiles is an indication of the heterogeneity that exists in farm data ${ }^{2}$. The $\mathrm{R} 2$ revealed that the variables in the model 
Table 4.6 Labor productivity model (male)

\begin{tabular}{llllll}
\hline & & \multicolumn{4}{c}{ Quantile regression } \\
\cline { 3 - 6 } Explanatory & & 25th & 50th & 75th & 90th \\
variables & OLS & quantile & quantile & quantile & quantile \\
\hline Input use index & 0.036 & 0.067 & -0.004 & -0.004 & $-0.114^{* *}$ \\
North (dummy) & $2.608 * * *$ & $0.818^{* * *}$ & $0.407 * * *$ & $0.261 * * *$ & 0.179 \\
Age & 0.118 & 0.027 & 0.015 & 0.011 & 0.043 \\
Education & -0.024 & -0.001 & -0.008 & -0.028 & 0.046 \\
Rural (dummy) & 0.073 & $-0.241 * *$ & $-0.211 *$ & $-0.298 * * *$ & -0.091 \\
Multiple & $0.556 * *$ & $0.001 * * *$ & $0.001 * * *$ & $0.001 * *$ & $0.001 * * *$ \\
$\quad$ cropping & & & & & \\
Own land & $-0.363 *$ & -0.563 & -0.068 & -0.195 & -0.093 \\
Land size & 0.134 & $0.001 *$ & $0.001 * * *$ & 0.001 & 0.001 \\
Household size & -0.257 & -0.759 & -0.004 & -0.002 & 0.019 \\
Has savings & -0.416 & -0.255 & 0.026 & $0.197 *$ & 0.054 \\
R2 & 0.561 & - & - & - & - \\
Adjusted R2 & 0.356 & - & - & - & - \\
Pseudo R2 & - & 0.1775 & 0.1708 & 0.1489 & 0.1266 \\
\hline
\end{tabular}

Source: Authors' computation from GHS 2012/2013 survey data

$*$ significant at $10 \%$ level; $* * 5 \%$ level; $* * * 1 \%$ level

explained about $56.1 \%$ of the variations in land productivity among males. Also the variables representing land size and savings that were not significant in the OLS were found to be significant in the 25th, 50th and 95th quantile regression.

The coefficient of the use of index was significant in the 90th quantile. The index, even though not significant, had a positive effect only in the 25 th quantile while it was negative in the other quantiles. This implies that input use only had an increasing effect on labor productivity among farmers who had the lowest productivity. Labor productivity increased significantly with farmers in the northern zones in the 25th, 50th and 75th, respectively. The coefficients indicate that the labor productivity in the northern zones was highest in the lowest quantile and decreased across the quantiles. Labor productivity also reduced significantly in rural areas across all the quantiles except in the 90th quantile while it increased among land owners in the 25th and 50th quantiles respectively. Labor productivity increased among male farmers who practiced multiple cropping across all the quantiles. 
Table 4.7 Labor productivity model (female)

\begin{tabular}{lccccc}
\hline \multirow{2}{*}{$\begin{array}{l}\text { Explanatory } \\
\text { variables }\end{array}$} & OLS & 25th & 50th & 75th & 90th \\
\cline { 3 - 6 } Input use index & -0.134 & 0.067 & -0.074 & -0.111 & $-0.152^{* * *}$ \\
North (dummy) & -0.341 & $1.397 * * *$ & $0.761 * * *$ & -0.137 & 0.127 \\
Age & 0.185 & 0.152 & -0.076 & -0.088 & -0.039 \\
Education & 0.268 & 0.079 & 0.099 & $0.973^{*}$ & 0.032 \\
Rural (dummy) & 0.417 & -0.005 & 0.286 & $0.959^{*}$ & 0.222 \\
Multiple cropping & -0.387 & $0.001 * * *$ & -0.002 & $0.001 * * *$ & $0.001 * * *$ \\
Own land & 2.015 & -0.649 & $-0.500^{*}$ & -0.479 & $2.544^{*}$ \\
Land size & 1.945 & 0.001 & $2.501 *$ & 0.001 & 2.232 \\
Household size & -0.001 & -0.055 & -0.009 & $0.155^{*}$ & $0.146^{* *}$ \\
Has savings & $0.068 *$ & 0.217 & $0.388^{*}$ & 0.147 & 0.347 \\
R2 & 0.539 & - & - & - & - \\
Adjusted R2 & 0.383 & - & - & - & - \\
Pseudo R2 & - & 0.1383 & 0.1167 & 0.1202 & 0.1919 \\
\hline
\end{tabular}

Source: Authors' computation from GHS 2012/2013 survey data

*significant at $10 \%$ level; $* * 5 \%$ level; $* * * 1 \%$ level

\subsubsection{Gender-Specific Labor Productivity Model (Female)}

In the female labor productivity model on Table 4.7, only one variable was significant in the OLS model while two were significant in the 25th quintile and four variables were significant in each of the other quantiles. The $\mathrm{R} 2$ reveals that the variables in the model explain about $53.9 \%$ of the variations in land productivity among females. Just like the male model, the input use index had a positive effect only in the 25th quantile while it was negative in the other quantiles. It was also only significant in the 90th quantile. Labor productivity among women in the north increased significantly in the 25th and 50th quantile while it increased significantly in the rural areas in the 75th quantile. Labor productivity increased among female farmers who practiced multiple cropping across all the quantiles while it decreased significantly among women who owned land in the 50th quantile and increased among those in the 90th quantile. The labor productivity among women also increased with household size in the 75th and 90th quantiles while it increased with women that had savings in the 50th quantile. 


\subsection{Conclusion}

The extent of input utilization and its effect on labor productivity based on gender was examined in the study. The use of inputs was generally low among both male and female farmers. Compared to males, female-managed farms in the South-South and South-West used more of hired labor. More man-hours were utilized on male-managed plots $(208,266.60 \mathrm{man} / \mathrm{hours})$ when compared to those managed by females $(176,592.20 \mathrm{man} /$ hours). Males had a higher level of labor productivity ( $\$ 9.07 /$ man-hour) when compared to females ( $\$ 4.86 /$ man-hour). Labor productivity decreased significantly with input use among both male and female as their level of productivity increased.

\subsubsection{Recommendations}

- Generally, only very few farmers had utilized inputs on their farms. The generally low productivity of the agricultural sector in Nigeria can be improved extensively through the availability of agricultural inputs and its efficient use by farmers. The agricultural policy of the country should be revised and effectively implemented by the Federal Government of Nigeria. This would not only promote farmer's access to resources but would also improve productivity.

- The use of fertilizer was particularly low among female-managed plots in the southern zones. Generally, even though more of them used other inputs, the quantity utilized was lower when compared to malemanaged plots. The implementation of gender-sensitive policies should be strengthened to increase the access of female farmers to production inputs.

- Females also used more hired labor in their production activities. The agricultural labor market in Nigeria needs to be standardized and productivity to improve the performance of labor and promote labor use efficiency among farmers.

- Labor productivity decreased significantly with input use among both male and female in the highest productivity quantile. The Ministry of Agriculture and Rural Development needs to organize trainings to 
build the capacity of farmers so as to enhance their resource use skills and production efficiency. With the increasing participation of women in agriculture, female farmers should be encouraged to participate in such training programs.

\section{Appendix}

Table 4.8 Descriptive statistics of explanatory variables used

\begin{tabular}{lcrrrrr}
\hline & Total & \multicolumn{3}{c}{ Male } & \multicolumn{3}{c}{ Female } \\
\cline { 2 - 7 } Variables & Freq. & $\%$ & Freq. & $\%$ & Freq. & $\%$ \\
\hline Age & & & & & & \\
$19-30$ & 151 & 5.83 & 149 & 6.51 & 2 & 0.66 \\
$31-40$ & 479 & 18.48 & 462 & 20.17 & 17 & 5.63 \\
$41-50$ & 613 & 23.65 & 562 & 24.54 & 51 & 16.89 \\
$51-60$ & 632 & 24.38 & 543 & 23.71 & 89 & 29.47 \\
$>60$ & 717 & 27.66 & 574 & 25.07 & 143 & 47.35 \\
Mean & 52.53 & & 51.53 & & 60.16 & \\
Standard dev. & 14.79 & & 14.79 & & 12.37 & \\
Education & & & & & & \\
No education & 1190 & 45.91 & 1034 & 45.15 & 156 & 51.66 \\
Primary & 596 & 22.99 & 546 & 23.84 & 50 & 16.56 \\
Secondary & 659 & 25.42 & 583 & 25.46 & 76 & 25.17 \\
Higher & 147 & 5.67 & 127 & 5.55 & 20 & 6.62 \\
Number of males & in household & & & & \\
0 & 62 & 2.39 & - & - & 62 & 20.53 \\
1-3 & 1581 & 61.00 & 1407 & 61.44 & 174 & 57.62 \\
4-6 & 814 & 31.40 & 754 & 32.93 & 60 & 19.87 \\
$>6$ & 135 & 5.21 & 129 & 5.63 & 6 & 1.99 \\
Household has savings & & & & & \\
Yes & 697 & 26.89 & 618 & 26.99 & 79 & 26.16 \\
No & 1672 & 73.11 & 1672 & 73.01 & 223 & 73.84 \\
Own land & & & & & & \\
Yes & 70 & 2.70 & 59 & 2.58 & 11 & 3.64 \\
No & 2231 & 97.30 & 2231 & 97.42 & 291 & 96.36 \\
Multiple cropping & 1750 & 67.52 & 1529 & 66.77 & 221 & 73.18 \\
yes & 842 & 32.48 & 761 & 33.23 & 81 & 26.82 \\
No & & & & & & \\
Mono cropping & 738 & 28.47 & 662 & 28.91 & 76 & 25.17 \\
Yes & 1854 & 71.53 & 1682 & 71.09 & 226 & 74.83 \\
No & & & & & \\
\hline
\end{tabular}

Source: Authors' computation from GHS 2012/2013 survey data 
Table 4.9 Variance inflation factor (VIF) test

\begin{tabular}{llll}
\hline & VIF & Tolerance & R-squared \\
\cline { 2 - 4 } Fertilizer & 1.11 & 0.9004 & 0.0996 \\
Pesticide & 1.16 & 0.8642 & 0.1358 \\
Herbicide & 1.16 & 0.8646 & 0.1354 \\
Animal traction & 1.28 & 0.7789 & 0.2211 \\
Mach/equip & 1.21 & 0.8294 & 0.1706 \\
Age & 1.10 & 0.9095 & 0.0905 \\
Education & 1.06 & 0.9471 & 0.0529 \\
Cropping system & 1.13 & 0.8851 & 0.1149 \\
No of males & 1.03 & 0.9688 & 0.0312 \\
No of animals & 1.04 & 0.9591 & 0.0409 \\
Savings & 1.02 & 0.9851 & 0.0149 \\
Mean VIF & 1.12 & & \\
\hline Source: Authors computa
\end{tabular}

Source: Authors' computation from GHS 2012/2013 survey data

Table 4.10 Result of PCA for inputs

The eigenvalues of the PCA for the inputs show that the first component has a variance of 1.28, and the second component has a variance of 1.13. The variance of the first and second component represents $25.7 \%$ and $22.6 \%$ of the total variance in the access to healthcare. The first and second components explain $48.3 \%$ of the total variance of the five indicators in the input use index. In the first component, pesticide and animal traction had a negative and reducing effect on the healthcare index while in the second component, only fertilizer had reducing effects

\begin{tabular}{lllll}
\hline Component & Eigenvalue & Difference & Proportion & Cumulative \\
\hline Comp1 & 1.285 & 0.155 & 0.257 & 0.257 \\
Comp2 & 1.131 & 0.169 & 0.226 & 0.483 \\
Comp3 & 0.961 & 0.071 & 0.192 & 0.676 \\
Comp4 & 0.890 & 0.158 & 0.178 & 0.853 \\
Comp5 & 0.732 & & 0.146 & 1.0000 \\
\hline
\end{tabular}

Principal components (eigenvectors) for first two components

\begin{tabular}{lrr}
\hline Variable & Comp1 & Comp2 \\
\hline Fertilizer & 0.353 & -0.517 \\
Pesticide & -0.104 & 0.618 \\
Herbicide & 0.149 & 0.519 \\
Animal traction & -0.689 & -0.002 \\
Mach/equip & 0.606 & 0.283 \\
\hline
\end{tabular}




\section{Notes}

1. Following International Rice research institute-IRRI (1991) and Khurana R.M. 1992, the time spent by hired female and child labor was adjusted to the hired male labor by multiplying the time they spent by 0.75 and 0.50 , respectively.

2. The heterogeneity in the data was confirmed with the F test which showed that significant difference existed in the productivity of labor across the quantiles. $\mathrm{F}=75.23(p<0.01)$.

\section{References}

Ajani, E. N., \& Igbokwe, E. M. (2011). Implication of Feminization of Agriculture on Women Farmers in Anambra State, Nigeria. Journal of Agricultural Extension, 15(1). https://doi.org/10.4314/jae.v15i1.4.

Anyaegbunam, H. N., Okoye, G. N., Asumugha, M. C., Ogbonna, T. U., Madu, N. N., \& Ejechi, M. E. (2010). 'Labour Productivity Among Small Holder Cassava Farmers in Southeast Agroecological Zone', Nigeria. African Journal of Agricultural Research, 5(21), 2882-2885.

Biniaz, A. (2014). Labour Productivity and Factors Affecting Its Demand in Paddy Farms in KB Province, Iran. TI Journal, Agricultural Science Developments, 3(7), 251-255.

Clark, J. T. (2013). Understanding the Gender Based Productivity Gap in Malawis Agricultural Sector. An unpublished thesis submitted to the Faculty of the graduate school of Arts and Sciences of Georgetown University, Washington, DC, April 16.

David, S. (2010). The Rural Non-farm Economy, Livelihood Strategies and Household Welfare. African Journal of Agricultural Research, 4(1), 82-109.

Edet, B. N., Edet, M. E., \& Agom, D. I. (2016). Impact of Institutional Funding on Agricultural Labour Productivity in Nigeria: A Co-integration Approach. Agricultural Science Research Journal, 6(2), 49-55.

Fabiyi, E. F., Danladi, B. B., Akande, K. E., \& Mahmood, Y. (2007). Role of Women in Agricultural Development and Their Constraints: A Case Study of Bilri Local Government Area, Gombe State, Nigeria. Pakistan Journal of Nutrition, 6(6), 676-680.

International Rice Research Institute (IRRI). (1991). Basic Procedures for Agroeconomic Research. International Rice Institute P.O.Box 933, 1099 Manila, Philippines. ISBN 97-1-22-0007-8. Retrieved from www.irri.org. 
Kaditi, E. A., \& Nitsi, E. I. (2009). A Two-Stage Productivity Analysis Using Bootsrapped Malmquist Indices and Quantile Regression. No 52845, selected paper presented at the 111th EAAE-IAAE seminar, Canterbury, UK, June $26-27$.

Kaditi, E. A., \& Nitsi, E. I. (2010). Applying Regression Quantiles to Farm Efficiency Estimation. Selected paper prepared for presentation at the Agricultural and Applied Economics Association 2010. AAEA, CAES and WAEA Joint Annual Meeting, Denver, Colorado, July 25-27.

Khurana R. M. (1992). Agricultural Development and Employment Patterns in India: A Comparative Analysis of Punjab and Bihar. The concept publishing company, A/15-16, Commercial block, Mohan Garden New Delhi 110059, India.

Kolenikov, S., \& Angeles, G. (2004). The Use of Discrete Data in PCA: Theory, Simulations and Applications to Socio Economic Indices. Working Paper WP 04 - 85. MEASURE Evaluation, Chapel Hill. Retrieved from http://www. cpc.unu.edu/measure/publications/wp-04-85.

Kwaramba P. K. (1997, December). The Socio-Economic Impact of HIVIAIDS on Communal Agricultural Systems in Zimbabwe. FES Economic Advisory Services Working Paper No 19.

Lastarria-corhiel, S. (2006). Feminization of Agriculture: Trends and Driving Forces. Background paper for the World development Report 2008. November 2006.

Manyong, V. M., Ikpi, A., Olayemi, J. K., Yusuff, S. A., Omonona, B. T., Okoruwa, V., \& Idachaba, F. S. (2005). Agriculture in Nigeria: Identifying Opportunities for Increased Commercialization and Investment. Ibadan: IITA.

McCullough, E. B. (2015). Labor Productivity and Employment Gaps in SubSaharan Africa. Policy Research Working Paper 7234, World Bank Group, Africa Region, Office of the Chief Economist, April.

Mohammed-Lawal, A., \& Atte, O. A. (2006). An Analysis of Agricultural Production in Nigeria. African Journal of General Agriculture, 2(1).

Obasi, O. O., \& Kanu, W. N. (2014). Gender Access to Farm Labour and Coping Strategies: Implication for Food Productivity in Imo State, Nigeria. International Journal of Development and Sustainability, 3(8), 1777-1781.

Ogunlela, Y. I., \& Mukhtar, A. A. (2009). Gender Issues in Agriculture and Rural Development in Nigeria: The Role of Women. Humanity and Social Sciences Journal, 4(1), 19-30.

Ogunniyi, L. T., Ajao, O. A., \& Adeleke, O. A. (2012). Gender Comparison in Production and Productivity of Cocoa Farmers in Ile Oluji Local Government 
Area of Ondo State, Nigeria. Global Journal of Science Frontier Research Agriculture Biology, 12(5), 59-63.

Okoye, B. C., Onyenweaku, C. E., Ukoha, O. O., Asumugha, G. N., \& Aniedu, O. C. (2008). Determinants of Labour Productivity on Small Holder Farms in Anambra State, Nigeria. Scientific Research and Essay, 3, 559-561.

Oluyole, K. A., Adebiyi, S., \& Adejumo, M. O. (2007). An Assessment of the Adoption of Cocoa Rehabilitation Techniques Among Cocoa Farmers in Ijebu East Local Government Area of Ogun State. Journal of Agricultural Research and Policies, 2(1), 56-60.

Oluyole, K. A., Dada, O. A., Oni, O. A., Adebiyi, S., \& Oduwole, O. O. (2013). Farm Labour Structure and Its Determinants Among Cocoa Farmers in Nigeria. American Journal of Rural Development, 1(1), 1-5.

Organisation for Economic Co-Operation and Development-OECD. (2011). Measuring Productivity: Measurement of Aggregate and Industry-Level Productivity Growth. An OECD Manual. Retrieved from www.SourceOECD.org.

Palacios-López, A., \& López, R. (2015). The Gender Gap in Agricultural Productivity: The Role of Market Imperfections. The Journal of Development Studies, 51(9), 1175-1192.

Phillip, D., Nkoya, E., Pender, J., \& Oni, O. A. (2009). Constraints to Increasing Agricultural Productivity in Nigeria: A Review. A Nigeria Strategy Support Program (NSSP). Background paper No NSSP 006, September.

Polyzos, S., \& Arabatzis, G. (2005). Labor Productivity of the Agricultural Sector in Greece: Determinant Factors and Interregional Difference Analysis. Discussion Paper Series, Department of Planning and Regional Planning, School of Engineering, University of Thessaly, 11(2), 209-226.

Ragasa, C. Berhane, G., Tadesse, F., \& Taffesse, A. S. (2012). Gender Differentials in Access to Extension Service and Agricultural Productivity. Ethiopia strategy program 2, ESSP Working paper 49.

Umar, H. S., Luka, E. G., \& Rahman, S. A. (2010). Gender Based Analysis of Labour Productivity in Sesame Production in Doma Local Government Area of Nasarawa State, Nigeria. Patnsuki Journal, 6(2), 61-68.

World Bank. (2013). Agriculture in Africa. Fact Sheet: The World Bank and Agriculture in Africa.

Worldometers. (n.d.). Nigeria Population Growth Rate. Retrieved February 11, 2015, from www.worldometers.info. 
Open Access This chapter is licensed under the terms of the Creative Commons Attribution 4.0 International License (http://creativecommons.org/licenses/ by/4.0/), which permits use, sharing, adaptation, distribution and reproduction in any medium or format, as long as you give appropriate credit to the original author(s) and the source, provide a link to the Creative Commons license and indicate if changes were made.

The images or other third party material in this chapter are included in the chapter's Creative Commons license, unless indicated otherwise in a credit line to the material. If material is not included in the chapter's Creative Commons license and your intended use is not permitted by statutory regulation or exceeds the permitted use, you will need to obtain permission directly from the copyright holder.

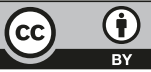

